\title{
Yield Estimation for a Single Purpose Multi-Reservoir System Using LP Based Yield Model
}

\author{
Deepak V. Pattewar ${ }^{1}$, Kalpeshkumar M. Sharma ${ }^{1}$, P. D. Dahe ${ }^{2}$ \\ ${ }^{1}$ Civil Engineering Department, M. G. M's College of Engineering, Nanded, India. \\ ${ }^{2}$ Civil Water Management, S. G. G. S College of Engineering and Technology, Nanded, India \\ Email: deepak_pattewar@yahoo.co.in,kalpeshkumar_sharma@yahoo.com
}

Received April 17, 2013; revised May 22, 2013; accepted July 1, 2013

Copyright (C) 2013 Deepak V. Pattewar et al. This is an open access article distributed under the Creative Commons Attribution License, which permits unrestricted use, distribution, and reproduction in any medium, provided the original work is properly cited.

\begin{abstract}
Application of optimization techniques for determining the optimal operation policy for reservoir is a major area in water resources planning and management. Linear programming, ruled by evolution techniques, has become popular for solving optimization problems in diversified fields of science. An LP-based yield model (YM) has been used to reevaluate the annual yield available from the reservoirs for irrigation. This paper extends the basic yield model and presents a yield model for a multiple-reservoir system consisting of single-purpose reservoirs. Optimum yield of reservoirs system is calculated by yield model. The objective is to achieve prespecified reliability for irrigation and to incorporate an allowable deficit in the annual irrigation target. The yield model is applied to a system of two reservoirs in the Manar River in India. This model can act as a better screening tool in planning by providing outputs that can be very useful in improving the efficiency and accuracy of detailed analysis methods such as simulation.
\end{abstract}

Keywords: Yield Model; Reservoir Operation; Irrigation Releases; Manar River

\section{Introduction}

Linear Programming (LP) is a commonly used optimization approach in water resources management. It is concerned with solving a special type of problem; one in which all relations among the variables are linear, both in constraints and the objective function to be optimized. An application of LP to reservoir operations has varied from simple straightforward allocation of resources to complex situations of operation and management. In the past, limitations of computing power meant that optimization was achieved by decomposing reservoir systems in time and space. These early models were predominantly deterministic, that is, they did not take into account the stochastic nature of inflows but rather were based on long-term average seasonal or monthly flows. However, they have gradually been improved. For example, Loucks [1] developed a stochastic LP technique for a single reservoir subject to random, serially correlated, flows. Subsequently, much more complicated stochastic models have been developed to reflect more realistically stream flow stochasticity, evaporation losses and more complex systems involving multiple reservoirs (Dandy G.C., Connarty M.C and Locks D.P. [2]; William
W. G. Yeh [3]). Under certain assumptions, non-linear problems can be linearized and LP equations solved by iteration or approximation procedures. The program MODSIM is a generic program based around LP approaches that has been developed specifically for modeling water resources systems and reservoir operation by Labadiee [4]. Sinha A.K., Rao B.V. and Lall U. [5] have studied optimal reservoir operation for irrigation, hydropower production which involved constrained linear optimization. Dahe P.D. and Srivastava D.K. [6] developed the basic yield model and presented a multiple yield model for a multiple reservoir system consisting of single purpose and multipurpose reservoirs. The objective was to achieve pre specified reliabilities for irrigation and energy generation and to incorporate an allowable deficit in the annual irrigation target. The results were analyzed for four cases. Srivastava D.K. and Taymoor A. Awachi [7] developed nested models which were applied in tandem using linear programming (LP), dynamic programming (DP), artificial neural networks (ANN), hedging rules (HRs), and simulation. An LP-based yield model (YM) has been used to reevaluate the annual yields available from the Mula reservoir for water supply and irrigation. 
This study presents a methodology to optimize the design of the multi-reservoir irrigation system by taking monthly inflow and initial storage and tries to predict the maximum possible releases using Linear programming based Yield model. The specific objectives of the present study can be stated as fallows:

1) To develop a Linear Programming based yield model for reservoir operation for a monthly time step.

2) Comparison of yield model and actual irrigation releases for single purpose irrigation reservoirs in Manar River.

3) To draw the conclusions from the interpretation of results obtained.

\section{Reservoir Yield Model}

The conceptualisation and details of the yield model on which the present model development is based are presented in Loucks et al. [8]. When reservoir yield with reliability lower than the maximum reliability is to be determined, the extent of availability of yield (or the allowable deficit in yield) during failure years can be specified. This is achieved by specifying a failure fraction for the yield during the failure years. The factor $\theta_{p, j}$ is used in the model to define the extent of available yield during failure years. The objective of this model is to maximize the yield for given capacity of the reservoir. Let $p$ denotes the exceedence probability for the yield. The index $j$ refers to a year and index $t$ refers to a within-year period. In this model only the firm yield is used.

The yield model given by Dahe and Srivastava [6] to determine single yield from a reservoir is as follows.

The formulation of the yield model is as follows:

Objective function

Maximize

$$
O y_{1}^{f, p}+O y_{2}^{f, p}
$$

Constraint

1) Over-year storage continuity

$$
\begin{aligned}
& s_{1, j-1}^{\mathrm{o}}+I_{1, j}-\theta_{1, p, j} O y^{f, p}-S p_{1, j}-E l_{1, j}=s_{1, j}^{\mathrm{o}} \\
& s_{2, j-1}^{\mathrm{o}}+I_{2, j}-\theta_{2, p, j} O y^{f, p}-S p_{2, j}-E l_{2, j}+S p_{1, j}=s_{2, j}^{\mathrm{o}}
\end{aligned}
$$

The over-the-year capacity is governed by the distribution of annual stream flows and the annual yield to be provided. The maximum of all the over-the-year storage volumes is the over-the-year storage capacity. It is possible to specify a failure fraction to define the allowable deficit in annual reservoir yield during the failure years in a single-yield problem. In the above equation, $O y_{1}^{f, p}+O y_{2}^{f, p}$ is the safe (firm) annual yield from Upper Manar reservoir and Lower Manar reservoir with reliability $p . \quad s_{1, j-1}^{o}$ and $s_{1, j}^{o}$ are the initial and the final over-the-year active storages in year $j$ for the Upper Manar reservoir and similarly for the Lower Manar $s_{2, j-1}^{\mathrm{o}}$ and $s_{2, j}^{\mathrm{o}}$ respectively; $I_{1, j}$ and $I_{2, j}$ are the inflows in year $j$ (Upper Manar and Lower Manar in Manar River); $\theta_{p, j}$ is the failure fraction defining the proportion of the annual yield from reservoir to be made available during the failure years to safeguard against the risk of extreme water shortage during the critical dry periods $\left(\theta_{p, j}\right.$ lies between 0 and 1, i.e., for a complete failure year $\theta_{p, j}=0$, for a partial failure year $0<\theta_{p, j}<1$, and for a successful year $\left.\theta_{p, j}=1\right) ; E l_{1, j}$ and $E l_{2, j}=$ evaporation loss in year $j$ and $S p_{1, j}$ and $S p_{2, j}$ excessrelease (spills) in year $j$;

2) Over-year active storage volume capacity

$$
\begin{aligned}
& s_{1, j-1}^{\mathrm{o}} \leq Y_{1} \\
& s_{2, j-1}^{\mathrm{o}} \leq Y_{2}
\end{aligned}
$$

The active over-year reservoir capacity $\left(Y_{1}\right)$ required for delivering a safe or firm annual yield in Upper Manar reservoir and active over-year reservoir capacity $\left(Y_{2}\right)$ required for delivering a safe or firm annual yield in Lower Manar reservoir

3) Within-year storage continuity

$$
\begin{gathered}
s_{1, t-1}^{w}+\beta_{1, t}\left(O y_{1}^{f, p}+\sum_{t} E l_{1, t}\right)-O y_{1, f, p}^{t}-E l_{1}^{t}=s_{1, t}^{w} \\
s_{2, t-1}^{w}+\beta_{2, t}\left(O y_{2}^{f, p}+\sum_{t} E l_{2, t}\right) \\
-O y_{2, f, p}^{t}-E l_{2}^{t}+0.10 \times O y_{1, f, p}^{t}=s_{2, t}^{w}
\end{gathered}
$$

Any distribution of the within-the-year yields differing from that of the within-the-year inflows may require additional active reservoir capacity. The maximum of all the within-the year storage volumes is the within-theyear storage capacity. In the above equation, $s_{1, t-1}^{w}, s_{2, t-1}^{w}$ and $s_{1, t}^{w}, s_{2, t}^{w}$ are the initial and the final within-theyear active storages at time $t ; \beta_{1, t}$ and $\beta_{2, t}$ are the ratio of the inflow in time $t$ of the modelled critical year of record to the total inflow in that year; and $E l_{1, t}$ and $E l_{2, t}$ are the within-the-year evaporation losses during time $t$. The inflows and the required releases are just in balance. So, the reservoir neither fills nor empties during the critical year.

4) Definition of estimated evaporation losses (Overyear)

$$
E 1_{1, j}=E 0_{1}+\left[s_{1, j-1}^{0}+\sum_{t}\left(\frac{s_{1, t-1}^{w}+s_{1, t}^{w}}{2}\right) \gamma_{1, t}\right] E l_{1}^{r}
$$




$$
E 1_{2, j}=E 0_{2}+\left[s_{2, j-1}^{0}+\sum_{t}\left(\frac{s_{2, t-1}^{w}+s_{2, t}^{w}}{2}\right) \gamma_{2, t}\right] E l_{2}^{r}
$$

5) Definition of estimated evaporation losses (Withinyear)

$$
\begin{gathered}
E 1_{1}^{t}=\gamma_{1, t} E 0_{1}+\left(s_{c r}^{o}+\frac{s_{1, t-1}^{w}+s_{1, t}^{w}}{2}\right) \gamma_{1, t} E l_{1}^{r} \\
E 1_{2}^{t}=\gamma_{2, t} E 0_{2}+\left(s_{c r}^{o}+\frac{s_{2, t-1}^{w}+s_{2, t}^{w}}{2}\right) \gamma_{2, t} E l_{2}^{r}
\end{gathered}
$$

6) Total reservoir capacity

$$
\begin{gathered}
Y_{1}+s_{1, t-1}^{w} \leq Y a_{1} \\
Y_{2}+s_{2, t-1}^{w} \leq Y a_{2}
\end{gathered}
$$

Sum of the over-the-year and the within-the-year storage capacities is equal to the active storage capacity of the reservoir.

7) Proportioning of yield in within-year periods

$$
\begin{aligned}
& O y_{1, f, p}^{t}=K_{1, t}\left(O y_{1}^{f, p}\right) \\
& O y_{2, f, p}^{t}=K_{2, t}\left(O y_{2}^{f, p}\right)
\end{aligned}
$$

$K_{1, t}$ and $K_{2, t}$ defines a predetermined fraction of annual reservoir yield to be supplied in the within-year yield in period $t$.

The Equations (1) to (15) present the Multi-reservoir yield model for Upper Manar and Lower Manar reservoir in Manar River.

\subsection{System Description: Manar River}

The Manar River, a tributary of Manjara River in Godavari basin, Maharashtra states in INDIA. In Manar River two medium project has constructed i.e. Upper Manar and Lower Manar reservoir for irrigation preposes Figure 1. Table 1 is the silent features of Upper Manar Pro-

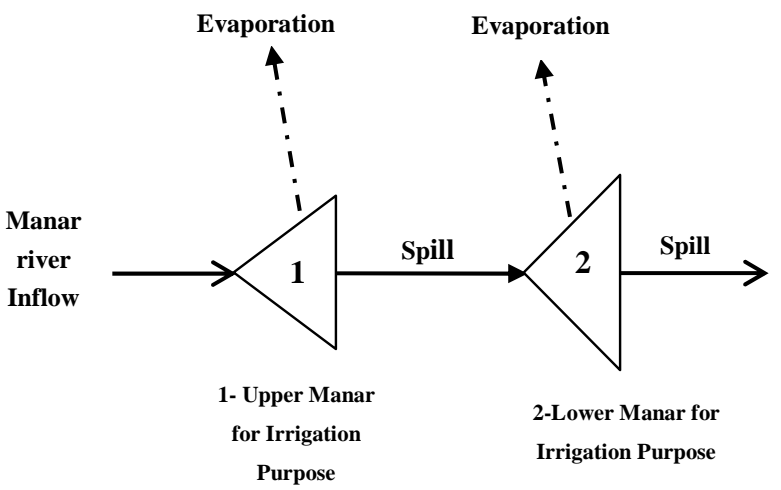

Figure 1. Line diagram of reservoir system on Manar River. ject Limboti reservoir and Lower Manar Project-Barul reservoir. A 37 years historic inflow data for the system considered is available as shown in Figures $\mathbf{2}$ and $\mathbf{3}$.

\subsubsection{Irrigation Parameters $\left(K_{t}\right)$ for Upper Manar Limboti Reservoir and Lower Manar Barul Reservoir}

The monthly proportions of the annual irrigation targets ( $K_{t}$ values) are worked out by considering the cropping patterns and irrigation intensities recommended by the agricultural officer. $K_{t}$ defines a predetermined fraction of reservoir yield the within-year period $t$. The $K_{t}$ values are given in Table 2.

\begin{tabular}{|c|c|c|}
\hline Particulars & Upper Manar & Lower Manar \\
\hline \multirow{2}{*}{$\begin{array}{l}\text { Scope of Scheme } \\
\text { Location }\end{array}$} & Irrigation Purpose & Irrigation Purpose \\
\hline & $\begin{array}{l}\text { Manar River at } \\
\text { Limboti }\end{array}$ & Manar River at Barul \\
\hline Catchment area & $987.60 \mathrm{Sq} \mathrm{Km}$ & 1585.08 Sq Km \\
\hline Gross storage capacity & $107.98 \mathrm{MCM}$ & $146.92 \mathrm{MCM}$ \\
\hline $\begin{array}{l}\text { Capacity of Live } \\
\text { Storage }\end{array}$ & $75.71 \mathrm{MCM}$ & 138.21 MCM \\
\hline $\begin{array}{l}\text { Capacity of } \\
\text { Dead Storage }\end{array}$ & $32.27 \mathrm{MCM}$ & $8.71 \mathrm{MCM}$ \\
\hline $\begin{array}{c}75 \% \text { dependable } \\
\text { yield(Project Report) }\end{array}$ & $162.50 \mathrm{MCM}$ & 205.76 MCM \\
\hline
\end{tabular}

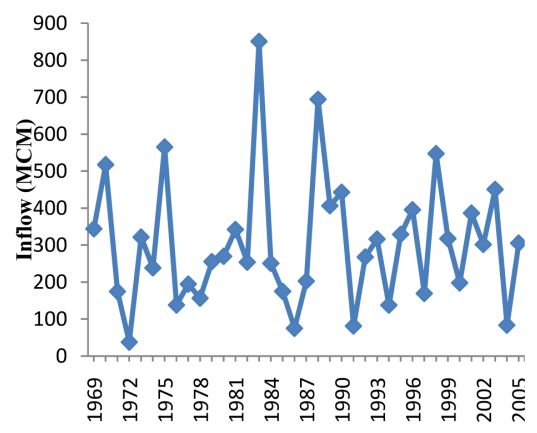

Figure 2. Inflow at Upper Manar-Limboti reservoir.

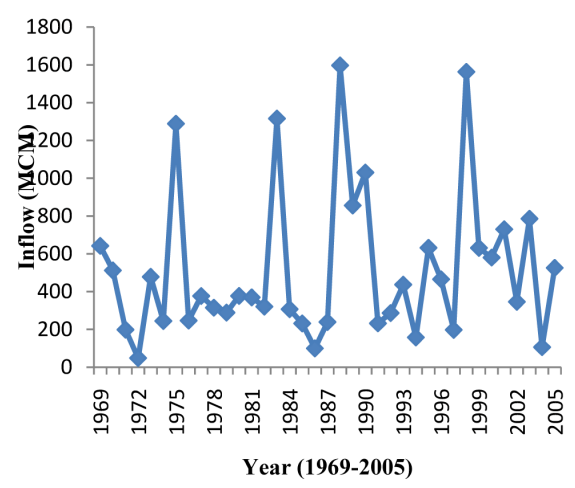

Figure 3. Inflow at Lower Manar-Barul reservoir.

Table 1. Silent features of Upper Manar and Lower Manar project in Manar River. 
Table 2. Within-year inflow approximation, irrigation and evaporation parameters used in the yield model for reservoirs on Manar River.

\begin{tabular}{ccccccc}
\hline Month & $\beta_{1, t}$ & $\beta_{2, t}$ & $\gamma_{t 1}$ & $\gamma_{t 2}$ & $K_{t 1}$ & $K_{t 2}$ \\
\hline June & 0.0522 & 0.0560 & 0.1330 & 0.0443 & 0.0215 & 0.1240 \\
July & 0.1580 & 0.1670 & 0.0686 & 0.0492 & 0.0151 & 0.0000 \\
Aug & 0.2967 & 0.2953 & 0.0589 & 0.0417 & 0.0186 & 0.0000 \\
Sept & 0.2289 & 0.2209 & 0.0568 & 0.0880 & 0.0299 & 0.0336 \\
Oct & 0.1490 & 0.1460 & 0.0575 & 0.0858 & 0.1618 & 0.0446 \\
Nov & 0.0363 & 0.0363 & 0.0540 & 0.0759 & 0.2347 & 0.1855 \\
Dec & 0.0186 & 0.0186 & 0.0450 & 0.0973 & 0.1794 & 0.1840 \\
Jan & 0.0160 & 0.0160 & 0.0547 & 0.0977 & 0.0842 & 0.1860 \\
Feb & 0.0103 & 0.0103 & 0.0623 & 0.1041 & 0.0634 & 0.0910 \\
March & 0.0112 & 0.0112 & 0.1004 & 0.1173 & 0.0667 & 0.0293 \\
April & 0.0119 & 0.0119 & 0.1302 & 0.1400 & 0.0706 & 0.0230 \\
May & 0.0109 & 0.0109 & 0.1787 & 0.0585 & 0.0541 & 0.0990 \\
\hline
\end{tabular}

\subsubsection{Approximation of Critical Within-Year Inflows $\left(\beta_{t}\right)$ Values for Upper Manar Limboti Reservoir and Lower Manar Barul Reservoir}

$\beta_{t}$ values are based on average monthly flows. The $\beta_{t}$ values based on average monthly flows for reservoir are given in Table 2.

\subsubsection{Evaporation Parameters of Reservoirs $\boldsymbol{\gamma}_{\boldsymbol{t}}$}

The average monthly evaporation depth at all the reservoirs is obtained from the Water Resources Department and available project reports. The evaporation volume loss due to dead storage $E 0_{1}=8.158$ and $E 0_{2}=11.30$ are obtained by product of the average annual evaporation depth and the area at dead storage elevation for respective reservoirs. The storage-area and storage-elevation relationship is taken for study. A linear fit for the storage-area data for each reservoir above the dead storage is obtained from the storage area relationship. The evaporation volume loss rate $E l_{1}^{r}=0.2880$ and $E l_{2}^{r}=0.4139$ are obtained by taking the product of the slope of the area elevation curve linearized above dead storage and the average annual evaporation depth at respective reservoirs. The parameter $\gamma_{t}$ (the fraction of the annual evaporation volume loss that occurs in within-year period t) is computed by taking the ratio of the average monthly evaporation depth to the average annual evaporation depth at respective reservoirs. The values of the $\gamma_{t}$ are given in the Table 2.

\section{Analysis and Results}

\subsection{Application of the Yield Model in Assessment of Manar River Yield}

The approximate model which includes within year periods for only one modelled critical year is known as the
Yield Model. The observed historical inflows of Manar River for 37 years (1969-2005) are used in computation of the yields from the reservoirs. Out of these a set of 9 lowest flow years $\left(3^{\text {rd }}, 4^{\text {th }}, 16^{\text {th }}, 17^{\text {th }}, 18^{\text {th }}, 23^{\text {rd }}, 25^{\text {th }}, 29^{\text {th }}\right.$ and $\left.36^{\text {th }}\right) 1971,1972,1984,1985,1986,1991,1993$, 1997 and $2004(\approx 25 \%$ of the years) were assumed as the common failure years in both reservoir, determined by the modified method of determining failure years by yield model. Thus remaining 28 years were successful years representing $75 \%$ annual project reliability. Thus, thirty seven over year and twelve within year periods were considered for analysis. The value of $\beta_{t}$ 's based on average monthly flows have been considered for the analysis and are presented in the Table 2. The within year yields from the reservoir for irrigation in a month are represented as a fraction of its annual yield. With the provision of $\theta_{p, j}$, the extent of failure in the annual yield from the reservoir during failure years was monitored as clear guidelines were not established for deciding its value. The value of $\theta_{p, j}$ for the project was determined using the YM with an objective to minimize its value. In Manar River, irrigation originally being the main project target was considered as a single yield or firm yield from the reservoir. The annual project reliability for irrigation was kept equal to $75 \%$. The value of $\theta_{p, j}$ was found to increase with the decrease in the annual yield from the reservoir. In Manar River two reservoirs (Upper ManarLimboti reservoir and Lower Manar-Barul reservoir) are constructed for the irrigation purposes.

For Upper Manar-Limboti reservoir with active storage capacity of 75.71 MCM and for Lower Manar-Barul reservoir with active storage capacity of $95.71 \mathrm{MCM}$, the yield is found out for Safe reservoir yield $\theta_{p, j}=1$ and $\theta_{p, j}$ $=0.00$ respectively. Calculated annual yield of Upper Manar-Limboti reservoir by yield model is 52.44 and 
107.24 MCM respectively and for Lower Manar-Limboti reservoir is 42.76 and 107.27 MCM respectively in Multi reservoir yield model analysis. Within-period water releases are shown in Table $\mathbf{3}$.

\subsection{Comparison of $\mathbf{Y M}$ and Actual Releases in Lower Manar-Barul Reservoir}

The main objective is to compute the yield that should be released to fulfill the total demand. Comparison of actual demand, releases and yield which are obtained from the model used is as follows. Multi-reservoir yield model based on the monthly inflow and monthly irrigation demands of the reservoir operation system is considered for the comparison. The Upper Manar-Limboti reservoir is recently constructed and has started operating from October 2010. Water releases data is not available for it hence only Lower Manar-Barul reservoir is taken for the comparison.

Table 4 gives the output of the model used for $75 \%$ reliable yield as well as demand and actual releases in the years which are considered in Lower Manar-Barul reservoir. The data available on actual releases of only 6 years is used for comparison. As per the Table 4 the actual release from the reservoir is maximum $98.79 \mathrm{MCM}$ in the year 2000-2001 and minimum is 68.49 MCM in year 2003-2004. Figure 4 shows comparison between

Table 3. Representing the monthly water releases for irrigation by approximate YM (Multi-reservoir) in Manar River.

\begin{tabular}{|c|c|c|c|c|c|c|}
\hline \multirow{2}{*}{ Month } & \multicolumn{3}{|c|}{ Safe Reservoir Yield (MCM) $\theta_{p, j}=1.00$} & \multicolumn{3}{|c|}{$75 \%$ reliable Yield $(\mathrm{MCM}) \theta_{p, j}=0.00$} \\
\hline & $\begin{array}{c}\text { Upper Manar } \\
\text { Limboti Reservoir }\end{array}$ & $\begin{array}{c}\text { Lower Manar } \\
\text { Barul Reservoir }\end{array}$ & $\begin{array}{c}\text { Total } \\
\text { Yield (MCM) } \\
\end{array}$ & $\begin{array}{c}\text { Upper Manar } \\
\text { Limboti Reservoir }\end{array}$ & $\begin{array}{c}\text { Lower Manar } \\
\text { Barul Reservoir }\end{array}$ & Total Yield (MCM) \\
\hline June & 1.127 & 5.302 & 6.429 & 2.305 & 13.301 & 15.606 \\
\hline July & 0.719 & 0.000 & 0.719 & 1.619 & 0.000 & 1.619 \\
\hline Aug & 0.975 & 0.000 & 0.975 & 1.994 & 0.000 & 1.994 \\
\hline Sept & 1.568 & 1.436 & 3.004 & 3.206 & 3.604 & 6.810 \\
\hline Oct & 8.485 & 1.907 & 10.392 & 17.352 & 4.784 & 22.136 \\
\hline Nov & 12.308 & 7.932 & 20.240 & 25.170 & 19.898 & 45.068 \\
\hline Dec & 9.408 & 7.868 & 17.276 & 19.239 & 19.737 & 38.976 \\
\hline Jan & 4.415 & 7.954 & 12.369 & 9.030 & 19.952 & 28.982 \\
\hline Feb & 3.324 & 3.891 & 7.215 & 6.799 & 9.761 & 16.560 \\
\hline March & 3.497 & 1.253 & 4.750 & 7.153 & 3.143 & 10.296 \\
\hline April & 3.702 & 0.983 & 4.685 & 7.571 & 2.467 & 10.038 \\
\hline May & 2.837 & 4.233 & 7.070 & 5.801 & 10.619 & 16.420 \\
\hline Total & 52.437 & 42.765 & 95.207 & 107.239 & 107.27 & 214.515 \\
\hline
\end{tabular}

Table 4. Values of actual demand, actual releases and yield model (YM with $75 \%$ reliable $\theta_{p, j}=0.00$ ).

\begin{tabular}{|c|c|c|c|c|c|c|c|c|c|c|}
\hline \multirow{2}{*}{ Sr. No } & \multirow{2}{*}{ Month } & \multirow{2}{*}{$\begin{array}{c}\text { Multi YM } \\
\text { (MCM) }\end{array}$} & \multirow{2}{*}{$\begin{array}{c}\text { Actual } \\
\text { Demand } \\
(\mathrm{MCM})\end{array}$} & \multicolumn{6}{|c|}{ Actual Water Releases in years 2000-2005 (MCM) } & \multirow{2}{*}{$\begin{array}{c}\text { Average } \\
\text { Water release } \\
(\mathrm{MCM})\end{array}$} \\
\hline & & & & $2000-2001$ & 2001-2002 & $2002-2003$ & $2003-2004$ & $2004-2005$ & $2005-2006$ & \\
\hline 6 & June & 13.30 & 25.51 & 12.25 & 11.29 & 11.57 & 8.5 & 10.46 & 11.63 & 10.95 \\
\hline 7 & July & 0 & 0 & 0 & 0 & 0 & 0 & 0 & 0 & 0.00 \\
\hline 8 & Aug & 0 & 0 & 0 & 0 & 0 & 0 & 0 & 0 & 0.00 \\
\hline 9 & Sept & 3.60 & 6.91 & 3.32 & 3.06 & 3.14 & 2.3 & 2.83 & 3.15 & 2.97 \\
\hline 10 & Oct & 4.78 & 9.18 & 4.41 & 4.06 & 4.16 & 3.06 & 3.76 & 4.18 & 3.94 \\
\hline 11 & Nov & 19.89 & 38.17 & 18.32 & 16.9 & 17.31 & 12.71 & 15.65 & 17.4 & 16.38 \\
\hline 12 & Dec & 19.73 & 37.86 & 18.18 & 16.76 & 17.17 & 12.61 & 15.52 & 17.26 & 16.25 \\
\hline 1 & Jan & 19.95 & 38.27 & 18.37 & 16.94 & 17.36 & 12.74 & 15.69 & 17.44 & 16.42 \\
\hline 2 & Feb & 9.76 & 18.72 & 8.99 & 8.29 & 8.49 & 6.23 & 7.66 & 8.53 & 8.03 \\
\hline 4 & April & 2.46 & 4.73 & 2.27 & 2.09 & 2.15 & 1.56 & 1.94 & 2.16 & 2.03 \\
\hline 5 & May & 10.61 & 20.37 & 9.78 & 9.01 & 9.24 & 6.78 & 8.35 & 9.28 & 8.74 \\
\hline \multicolumn{2}{|c|}{ Yield } & 107.26 & 205.75 & 98.79 & 91.07 & 93.32 & 68.49 & 84.33 & 93.78 & 88.30 \\
\hline
\end{tabular}




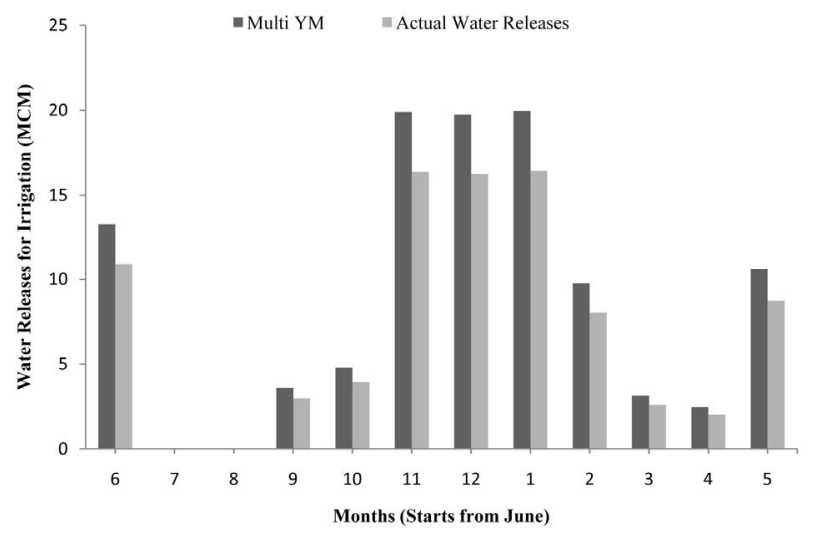

Figure 4. Comparison of actual releases and releases obtained from yield model.

monthly water releases, monthly demand and monthly yield by yield model. From the figure it is very clear that in the month of June, December and January the reservoir releases are comparable with the yield model, where as the actual demand is very large as compared to the actual releases from the reservoir except in the month February, March and April. It can be seen from the Figure 4 that the releases are negligible in the period of Kharif Crop i.e. June, July, August, September and mid of October. Whereas the releases are more in the period of Rabbi Crop (i.e. from October to February) and in Hot Weather crop period (i.e. from February to May).

The Yield model can be used for yield assessment with specified reliabilities and thus assists in the effective management and design of irrigation reservoir system. Yield model provides a better alternative to the deterministic full optimization model by the way of reduction in size and provides sufficiently accurate results. It also allows determination of annual yield with a given reliability less than the maximum reliability. There is also a provision of determining the percentage of annual yield to be supplied during failure years.

\section{Conclusion}

The study of multi-reservoir operation in Manar River is carried out using LP based yield model. Identification and screening of the feasible solution to provide potential candidates for detailed evaluation is a crucial stage during the search for optimal solution of real life problems. Mathematical optimization models play a vital role in this regard. The overall effort in handling real life systems can be significantly reduced with screening models capable of better representing the system and providing fewer and more accurate candidate solutions for detailed evaluation which is proportional to the number of candidate solutions to be evaluated and their proximity to the optimal solution. The yield model is studied for the two cases, which are safe reservoir yield model and yield model with $75 \%$ reliability of flow with complete failure. In the case of complete failure, the annual firm yield provided is zero during the failure years. The yield model is capable of considering the reliability of annual yield. It can also include the concept of complete or partial failure during the failure years. The yield model for reservoir system developed in this study successfully addresses the aspects of incorporating the desired reliabilities for different purposes, as well as an allowable deficit criterion for annual irrigation target in a reservoir systems consisting of a Multi reservoir irrigation system. It can act as a better screening tool in planning. Being an optimization model, no initial policy is needed for the analysis of reservoir systems. The model is general enough and could be applied to similar reservoir systems.

\section{REFERENCES}

[1] D. P. Loucks, "Computer Models for Reservoir Regulation," Journal of the Sanitary Engineering Division, Vol. 94, No. 4, 1968, pp. 657-671.

[2] G. C. Dandy, M. C. Connarty and D. P. Loucks, "Comparison of yield assessment of multiple reservoir systems," Journal of Water Resources Planning and Management, Vol. 123, No. 6, 1997, pp. 350-358.

[3] W. W. G. Yeh, "Reservoir Management and Operation s Models: A State-of-the-Art Review," Water Resources Research, Vol. 21, No.12, 1985, pp. 1797-1818. doi:10.1029/WR021i012p01797

[4] J. W. Labadie, "Optimal Operation of Multireservoir Systems: State-of-the-Art Review," Journal of Water Resources Planning and Management, Vol. 130, No. 2, 2004, pp. 93-111. doi:10.1061/(ASCE)0733-9496(2004)130:2(93)

[5] A. K. Sinha, B. V. Rao and U. Lall, "Yield Model for Screening Multi Purpose Reservoir Systems," Journal of Water Resources Planning and Management, Vol. 125, No. 6, 1999, pp. 325-332. doi:10.1061/(ASCE)0733-9496(1999)125:6(325)

[6] P. D. Dahe and D. K. Srivastava, "Multipurpose Multiyield Model with Allowable Deficit in Annual Yield," Journal of WRPM, Vol. 128, No. 6, 2002, pp. 406-414.

[7] D. K. Srivastav and T. A. Awchi, "Storage-Yield Evaluation and Operation of Mula Reservoir, India," Journal of Water Resources Planning and Management, Vol. 135, No. 6, 2009, pp. 414-425. doi:10.1061/(ASCE)0733-9496(2009)135:6(414)

[8] D. P. Loucks, J. R. Stedinger and D. A. Haith, "Water Resource Systems Planning and Analysis," Prentice-Hall, Inc., Englewood Cliffs, 1981. 


\section{Appendix: Notation}

The following symbols are used in this paper:

$O y_{1}^{f, p}=$ Annual firm Upper Manar reservoir yield.

$O y_{2}^{f, p}=$ Annual firm Lower Manar reservoir yield.

$s_{1, j-1}^{o}=$ Initial storage of Upper Manar reservoir at the beginning of year $j$.

Initial storage of Lower Manar reservoir at the beginning of year $j$.

$s_{1, j}^{\mathrm{o}}=$ Final storage of Upper Manar reservoir at the beginning of year $j$.

$s_{2, j}^{\mathrm{o}}=$ Final storage of Lower Manar reservoir at the beginning of year $j$.

$S p_{1, j}=$ Excess release in Upper Manar reservoir in year $j$.

$S p_{2, j}=$ Excess release in Lower Manar reservoir in year $j$.

$I_{1, j}=$ Annual inflow at Upper Manar reservoir site in year $j$.

$I_{2, j}=$ Annual inflow at Upper Manar reservoir site in year $j$.
$E l_{1, j}, E l_{2, j}=$ Annual evaporation volume loss from reservoir in year $j$.

$E l_{1}^{t}, E l_{2}^{t}=$ Evaporation volume loss from reservoir in period $t$.

$\beta_{1, t}, \beta_{2, t}=$ Fraction of total annual yield for assumed critical period inflow in Uppe Manar reservoir and Lower Manar reservoir.

$Y_{1}, Y_{2}=$ Over-year storage capacity of Upper Manar reservoir and Lower Manar reservoir.

$Y a_{1}, Y a_{2}=$ Total active storage capacity of Upper Manar reservoir and Lower Manar reservoir.

$K_{1, t}, K_{2, t}=$ Percentage fraction of annual irrigation target in period $t$ in Upper Manar and Lower Manar reservoir.

$s_{1, t-1}^{w}, s_{2, t-1}^{w}=$ Initial within-year storage volume in period $t$ in Upper Manar reservoir and Lower Manar reservoir.

$s_{1, t}^{w}=$ Final within-year storage volume in period $t$ in Upper Manar reservoir.

$\mathrm{MCM}=$ Million Cubic Meter. 